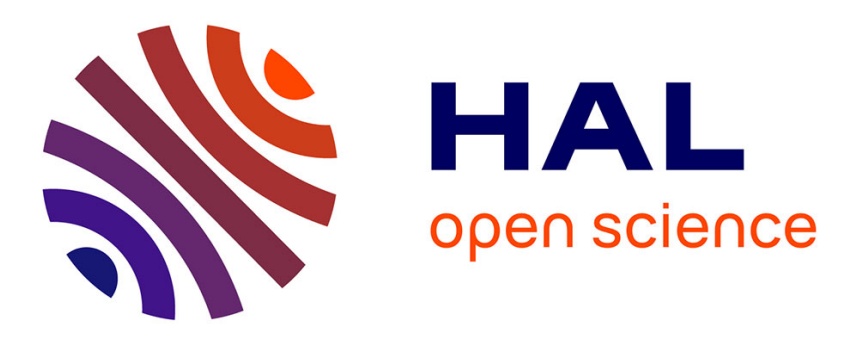

\title{
Multicriteria-Oriented Optimization of Building Energy Performances: The Annex 72 IEA-EBC Experience
}

Francesco Montana, Sonia Longo, Harpa Birgisdottir, Maurizio Cellura, Rolf

Frischknecht, Francesco Guarino, Benedek Kiss, Bruno Peuportier, Thomas Recht, Eleonora Riva Sanseverino, et al.

\section{To cite this version:}

Francesco Montana, Sonia Longo, Harpa Birgisdottir, Maurizio Cellura, Rolf Frischknecht, et al.. Multicriteria-Oriented Optimization of Building Energy Performances: The Annex 72 IEA-EBC Experience. Energy systems evaluation (volume 2), pp.239 - 260, 2021, 10.1007/978-3-030-67376-5_10 . hal-03379951

\section{HAL Id: hal-03379951 \\ https://hal.science/hal-03379951}

Submitted on 15 Oct 2021

HAL is a multi-disciplinary open access archive for the deposit and dissemination of scientific research documents, whether they are published or not. The documents may come from teaching and research institutions in France or abroad, or from public or private research centers.
L'archive ouverte pluridisciplinaire HAL, est destinée au dépôt et à la diffusion de documents scientifiques de niveau recherche, publiés ou non, émanant des établissements d'enseignement et de recherche français ou étrangers, des laboratoires publics ou privés. 


\section{Multicriteria-Oriented Optimization}

of Building Energy Performances: The Annex 72 IEA-EBC Experience

Francesco Montana, Sonia Longo, Harpa Birgisdottir, Maurizio Cellura, Rolf Frischknecht, Francesco Guarino, Benedek Kiss, Bruno Peuportier, Thomas Recht, Eleonora Riva Sanseverino, and Zsuzsa Szalay

Abstract This chapter describes the research experience of the International Energy Agency - Energy in Buildings and Communities Programme Annex 72 members on the application of multi-objective optimization processes for the selection of design or retrofit actions that allow for improving different aspects (energy, environmental, economic, etc.) of buildings in a life cycle perspective. Thirteen case studies were examined focussing on methodologies, applications and results and deriving generic conclusions and guidelines for building designers and decision-makers.

Keywords Optimization · Life cycle • Buildings · Energy performance • Environmental impacts

\section{Introduction}

The building sector is one of the most impacting on the energy demand and on the environment in developed countries, together with industry and transports [1]. This is well represented in Fig. 1, where the trend of primary energy consumption in final F. Montana (B) - S. Longo (B) - M. Cellura · F. Guarino - E. Riva Sanseverino

Department of Engineering, University of Palermo, Palermo, Italy

e-mail: francesco.montana@unipa.it

S. Longo

e-mail: sonia.longo@unipa.it

H. Birgisdottir

Danish Building Research Institute, Aalborg University Copenhagen, Copenhagen, Denmark

R. Frischknecht

Treeze Ltd., Uster, Switzerland

B. Kiss $\cdot$ Z. Szalay

Department of Construction Materials and Technologies, Budapest University of Technology and

Economics, Budapest, Hungary

B. Peuportier - T. Recht

Center for Energy Efficiency of Systems, MINES ParisTech, PSL Research University, Paris, France

(C) The Author(s), under exclusive license to Springer Nature Switzerland AG 2021

J. Ren (ed.), Energy Systems Evaluation (Volume 2), Green Energy and Technology, https://doi.org/10.1007/978-3-030-67376-5_10

239

240 M. Francesco et al.

Fig. 1 Primary energy consumption trend in final uses in EU [1]

uses in European Union (EU) is shown, with the building sector being included in households and commercial categories. Further detail is provided in Fig. 2, where the share in 2017 is reported.

$0 \%$

$5 \%$

$10 \%$

$15 \%$

$20 \%$

$25 \%$

$30 \%$

$35 \%$

Households Commercial \&

public services

Industry Transports Other Sectors

Fig. 2 Primary energy consumption in final uses in EU in 2017 [1]

Multicriteria-Oriented Optimization of Building Energy ... 241

A big share of this consumption can be ascribed to thermal uses, mainly due to poor buildings envelope and inefficiencies in heating, ventilation and air-conditioning (HVAC) plants [2].

With the aim of reducing the energy consumption of the building sector, EU emitted a series of energy performance of building directives, introducing the topic of nearly zero-energy building (nZEB) [3] and promoting deep renovations in the existing building stock [4]. 
The design process of a nZEB, and in general of a low-energy building, is generally composed by the following steps:

- Building thermal loads reduction through interventions on the envelope transmittance;

- Passive strategies employment, attributing part of the thermal loads removal to natural phenomena;

- Installation of efficient HVAC systems, as low temperature heating or high temperature cooling systems;

- Integration of renewable energy system technologies to cover as much as possible the residual loads.

Furthermore, according to EU directives, nZEBs should also be cost-efficient as well as energy-efficient, thus requiring to compare a set of interventions on the building to identify the optimal combination of strategies to implement. The economic point of viewis also a key issue for the investors, usually aiming at reaching their result with the minimum disbursement. Furthermore, the building inhabitants would prefer to enjoy a comfortable dwelling, aspect that in some cases can be hardly ensured together with the energy efficiency and the cost-optimality.

For what above, the adoption of a multicriteria approach is often required in the low-energy buildings sector. In detail, one of the most suitable approaches is to integrate the preliminary building design (or refurbishment) phase in an optimization problem, allowing to rapidly comparemany alternatives and to identify the most adapt interventions. In order to take into account for the different points of view of policy makers, investors and inhabitants, a multi-objective approach is also recommended. A further step forward may also be done considering that the operating energy reduction risks to be accompanied with a high rising in the energy used to build the envelope and equipment components (embodied energy), e.g. synthetic insulation materials or building automation systems, and also in the embodied environmental impacts as greenhouse gas emissions. In order to take into account this additional aspect, the multi-objective optimization of buildings needs a holistic approach integrating the energy analysis, the economic evaluation, the life cycle thinking, i.e. the application of the life cycle assessment (LCA) methodology [5-7], and other types of analyses.

This chapter illustrates and reviews the contribution of the International Energy

Agency - Energy in Buildings and Communities (IEA-EBC) Programme Annex 72 members to the life cycle multi-objective optimization of buildings performance, comparing methodologies, applications and results and deriving generic conclusions and guidelines from a collection of case studies.

242 M. Francesco et al.

\section{The IEA-EBC Annex 72}

The IEA-EBC Annex 72 focuses on the assessment of the primary energy demand, greenhouse gas emissions and environmental impacts of buildings during production, construction, use (including repair and replacement) and end of life (dismantling), i.e. during the entire life cycle of buildings [8].

Annex 72 comprises five main Subtasks (1-Harmonized methodology guidelines, 2-Building assessment tools, 3-Case studies, 4-Building sector LCA databases, 5-Dissemination) and aims at establishing a common methodology guideline to assess the life cycle energy and environmental impacts caused by buildings, at establishing methods for the development of specific environmental benchmarks for different types of buildings, at deriving guidelines and tools for building design and planning for the stakeholders (architects, planners, researchers, etc.), at developing or examining case studies focussed to some research issues and for deriving empirical benchmarks, and at developing national or regional databases with life cycle assessment data for the construction sector.

Within the Subtask 3, Activity 3.3 deals with the following problem: a specific design or retrofit action can allow for reducing the energy impact and some environmental or economic impacts of the building, but it can cause the increase of other environmental impacts as well (e.g. the use of electricity from PV instead of electricity from a country-specific grid allows for reducing the impact on global warming potential but causes an increase of the impact on land use).

The research issue is to avoid the shift of impacts from one impact category to another and to identify, among a group of solutions (e.g. different thicknesses of 
insulation or different types of insulation), the best ones (e.g. the best thickness of insulation or the best type of insulation) that allow for obtaining an "optimum" among the examined energy and environmental indexes, also taking into account other aspects such as the economic one. The optimization techniques can be applied to solve the above issue.

In this context, the goal of Activity 3.3 is to examine selected case studies in order to classify and characterize different approaches aimed at the optimization of the life cycle energy, environmental, economic and other performance of new buildings and renovation projects and to assess the potential of optimization strategies in order to provide some guidelines for building design and decision-making.

\section{Review of the Annex 72 Case Studies}

\subsection{Introduction}

Within the context of the Annex 72, a set of thirteen case studies related to the optimization of life cycle performance of buildings was collected and reviewed. Multicriteria-Oriented Optimization of Building Energy ... 243

The approaches and the outcomes of these studies were analysed and compared in this chapter, in order to identify a generic framework and to draw guidelines for the scientific community. In this section, a brief review of the analysed case studies is provided, reporting some details on each aspect of a typical optimization study.

\subsection{Optimization Software, Approaches and Algorithms}

The studies reviewed in this work can be categorized according to different aspects. Regarding the aim of the study, most of these thirteen works analysed the refurbishment of existing buildings [9-15], while three of them focussed on the early design stage of residential buildings [16,17], and one just examined the optimal concrete quantity and quality, disregarding the operating phase and the energy demand for air conditioning [18]. Only one of the examined buildings was optimized to reach the plus-energy level [16], while in most of the other studies the installation of renewables and the annual energy balance were not taken into account.

Considering the developers of the studies, six of them were performed by the research group of the Bauhaus-University Weimar [9-12, 18], four studies by the group from the University of Palermo [13-15], two studies came from the Budapest University of Technology and Economics [17] and the last work was developed by the MINES ParisTech researchers [16].

Most of the studies [9-12, 17, 18] were developed in Rhinoceros CAD environment [19], since this tool has a user-friendly framework and allows for integrating many aspects of the building design in a unique tool through many plug-ins available on its library. Two studies [13, 14] were modelled on SketchUp 3D CAD [20], using other tools for the optimization; one did not require a CAD modelling phase [15] and one was entirely developed in Pleiades [21], a French tool able to manage the $3 \mathrm{D}$ modelling, the energy simulation, the optimization process and the life cycle assessment [16].

In the reviewed studies, the use phase energy demand of the building was assessed mainly through a dynamic building performance simulation (BPS) software, with EnergyPlus [22] being themost popular [9-11, 13, 14], since it allows for the connection with both Rhinoceros and SketchUp, while four studies [12, 15, 17] adopted energy calculations based on the quasi-stationary seasonal method described on the European standard EN ISO 13790 [23] or on the German standard DIN V 18599 [24]. Many building performance optimization (BPO) tools and algorithms were employed in these studies: MOBO Multi-Objective Building Optimization tool [25, 26] was chosen in three studies [13-15], three Rhinoceros plug-ins for the optimization, namely Galapagos [9, 10, 18], Octopus [11, 17] and GOAT [11, 12], and MATLAB programming environment [14] were used in the other studies. The first outcome of this review is the great variability in the adoption of software tools, since the researchers were often forced to combine many software and plug-ins 244 M. Francesco et al. to perform their studies, with Pleiades being the unique commercial tool for the integration of all these aspects in the same platform. The same outcome was previously observed by Gilles et al. in 2017, discussing on the difficulties in the interactions between building performance simulators and life cycle assessment studies [27]. 
Analysing the optimization approach, six studies adopted a single-objective optimization approach [9-12,17, 18], while the remaining seven employed multiobjective algorithms [11, 13-17]. Nevertheless, some single-objective optimization studies also assessed additional life cycle impact indicators, although they were not optimized [9, 10, 18]. Moreover, some studies also evaluated the thicknesses of insulationmaterials minimizing many life cycle impact indicators, comparing the optimal retrofit actions $[12,17]$.

Almost all the studies adopted heuristic algorithms,mainly genetics, with the only exception of two case studies that adopted a dual step approach and employed the branch-and-bound algorithm in the second step [14]. This is a common aspect, since most of the optimization problems in engineering are highly nonlinear, preventing the adoption of exact deterministic algorithms based on derivatives evaluation, and heuristic and meta-heuristic algorithms are usually preferred. Moreover, the evaluation of one or more objective functions through a simulation-based optimization almost obliges the adoption of a heuristic approach.

Some studies involved the single-objective genetic algorithm available on Galapagos tool $[9,10,18]$ and the optimization plug-in of Rhinoceros Grasshopper modelling environment, while other researchers preferred the CRS2 [11, 12] or HypE [17] algorithms, also working on Rhinoceros. Unfortunately, according to a review performed by Wortmann [28] on the algorithms available on Rhinoceros, the genetic algorithm of Galapagos plug-in is considered the worst performing one and even the CRS2 algorithm was disregarded in this study, while the author recommends RBFOpt algorithm available on the Opossum plug-in. The multi-objective algorithms employed were NSGA-II $[13,16]$, since it is one of the most popular in scientific literature [29], and also HypE [17] and Omni-Optimizer [14, 15].

A recap of the main information provided so far is given in Table 1, while a visual representation of the studies developed is shown in Fig. 3, with the pins indicating how many studies were developed in each location and the logos indicating the adopted software tools.

The importance of selecting the most adapted algorithm was briefly discussed in [15], where the four multi-objective algorithms available inMOBO were compared, also changing the algorithm parameters, in order to identify the most suitable one. Only NSGA-II, aNSGA-II and Omni-Optimizer were illustrated, since the Random Search algorithm did not provide any feasible solution. The performance of these algorithms can be compared through the visualization of the resulting bi-dimensional Pareto Fronts, shown in Figs. 4 and 5, and through the number of the resulting feasible solutions and optimal compromise solutions (Pareto front), as reported in Table 2. It is evident that, although 200 generations were set, the aNSGA-II algorithm was not able to reach the Pareto front, both with 16 and 40 individuals. Omni-Optimizer instead identified good solutions with 16 individuals and 500 generations, but the best Multicriteria-Oriented Optimization of Building Energy ... 245

Table 1 Recap of the main features of the reviewed studies

Aim Developed by BPS BPO Approach Algorithm Reference

Design of a plus-energy

house

MINES ParisTech Pleiades (COMFIE

module)

AMAPOLA

(developed in Python)

Multi-objective NSGA-II genetic

algorithm

[16]

Refurbishment Bauhaus-University

Weimar

EnergyPlus Galapagos plug-in for

Grasshopper

(Rhinoceros)

Single-objective Evolutionary

algorithm

[10]

Refurbishment Bauhaus-University

Weimar

EnergyPlus Galapagos plug-in for

Grasshopper 
(Rhinoceros)

Single-objective Evolutionary

algorithm

[9]

Design of a garage Bauhaus-University

Weimar

Non necessary Galapagos plug-in for

Grasshopper

(Rhinoceros)

Single-objective Evolutionary

algorithm

[18]

Refurbishment Bauhaus-University

Weimar/Fraunhofer

Institute

EnergyPlus GOAT plug-in for

Grasshopper

(Rhinoceros)

Single-objective CRS2 evolutionary

algorithm

[11]

Refurbishment Bauhaus-University

Weimar/Fraunhofer

Institute

EnergyPlus Octopus plug-in for

Grasshopper

(Rhinoceros)

Multi-objective Genetic algorithm [11]

Refurbishment Bauhaus-University

Weimar

Grasshopper.

Quasi-steady state

approach based on DIN

V 18599

GOAT plug-in for

Grasshopper

(Rhinoceros)

Single-objective CRS2 evolutionary

algorithm

[12]

Design Budapest University of

Technology and

Economics

Grasshopper.

Quasi-steady state

approach based on ISO

13790

Octopus plug-in for

Grasshopper

(Rhinoceros)

Single-objective HypE genetic

algorithm

[17]

(continued)

246 M. Francesco et al.

Table 1 (continued)

Aim Developed by BPS BPO Approach Algorithm Reference

Design Budapest University of

Technology and

Economics

Grasshopper.

Quasi-steady state

approach based on ISO

13790

Octopus plug-in for

Grasshopper

(Rhinoceros)

Multi-objective HypE genetic

algorithm

[17]

Refurbishment University of Palermo EnergyPlus MOBO; MATLAB Multi-objective NSGA-II genetic 
algorithm;

branch-and-bound

MILP algorithm

$[13,14]$

Refurbishment University of Palermo EnergyPlus MOBO; MATLAB Multi-objective NSGA-II genetic algorithm;

branch-and-bound

MILP algorithm

$[13,14]$

Refurbishment University of

Palermo/Aalborg

University

Be18. Quasi-steady state

approach based on ISO

13790

MOBO Multi-objective Omni-Optimizer

genetic algorithm

[15]

Refurbishment University of Palermo EnergyPlus MOBO; MATLAB Multi-objective Omni-Optimizer genetic algorithm;

branch-and-bound

MILP algorithm

[14]

Multicriteria-Oriented Optimization of Building Energy ... 247

MOBOC

MOBOC

Fig. 3 Visual representation of the studies reviewed in this work

0

50000

100000

150000

200000

250000

300000

350000

400000

250035004500550065007500

Embodied Global Warming

Potential [kg CO2_eq]

Use Phase Final Energy Demand [MWh]

aNSGA II 16-200

aNSGA II 40-200

NSGA II 40-200

Omni-Optimizer 40-200

Omni-Optimizer 16-500

Fig. 4 Comparison of bi-dimensional Pareto fronts from 5 multi-objective algorithms used in [15] relating use phase final energy demand against embodied GWP

248 M. Francesco et al.

2000000

3000000

4000000

5000000

6000000

7000000

250035004500550065007500

Investment Cost [DKK]

Use Phase Final Energy Demand [MWh]

aNSGA II 16-200

aNSGA $\|$ 40-200

NSGA II 40-200

Omni-Optimizer 40-200

Omni-Optimizer 16-500

Fig. 5 Comparison of bi-dimensional Pareto fronts from 5 multi-objective algorithms used in [15] relating use phase final energy demand against investment cost

Table 2 Comparison of 5 multi-objective algorithms used in [15] according to the number of alternatives set for the optimization and the resulting number of feasible and optimal solutions Alternatives Feasible solutions 
Omni-Optimizer

$16-500$

800049482150267

results were obtained in the optimization with 40 individuals and 200 generations.

The NSGA-II algorithm solutions were sparser than the others.

A study on the parameter tuning in NSGA-II algorithm was conducted in [30], based on the hypervolume indicator (also called metric) which is a measure of both intensification and diversification of the optimization. On the basis of a reference variant, best compromises two pairs of parameters were explored: population size $(\mathrm{P})$ and number of evaluations, and crossover (C) and mutations (M) rates (in \%). For an equivalent number of evaluations after initialization, a large population size (P2000, M15 and C80 in Fig. 6) reduces the number of generations, degrading the research intensification. On the contrary, a small population size (P20, M15 and C80) speeds up the intensification at the beginning of optimization but quickly reaches its Multicriteria-Oriented Optimization of Building Energy ... 249

Fig. 6 Hypervolume evolution versus the number of model evaluations (after initialization) with 5 parameter settings [30]

limit by lack of diversification. Compared to a quasi-random search reproduced with a mutation rate of $100 \%$ and a crossover rate of $0 \%$ (P200, M100 and C0), the optimization by artificial evolution through NSGA-II with a standard tuning (P200, M15 and C80) is much more efficient. In this case study, the diversity produced by the crossover operator is sufficient to effectively conduct the research, leading to setting the mutation rate at $0 \%$ (P200, M0 and C100).

\subsection{Objective Functions and Variables}

\subsubsection{Objective Functions}

The objective functions minimized in the reviewed studies may be grouped in three categories: use phase performance, LCA embodied impacts and economic aspects. Almost all of the studies evaluated the use phase performance, since it is the most widely adopted criterion for the assessment of the energy efficiency. All the studies optimized the use phase of the building employing the global warming potential (GWP) as objective function, suggesting that this indicator appears asmore important than the use phase energy demand, even if usually the GWP and energy consumption are dependent each other. Some studies, both single and multi-objective, also assessed other LCA indicators. In detail, although some works $[12,17]$ described singleobjective optimizations, many indicators wereminimized separately in order to show the dependency of the optimal interventions on the objective function. Other studies, based on a two-step approach, optimized the use phase final energy demand in a first run where only the building envelope components were employed as variables, while 250 M. Francesco et al.

in the second step this value was used to identify the optimal equipment minimizing the use phase primary energy, GWPand operating costs. The unique work neglecting the use phase is the study by Hollberg et al. [18], where a case study on the design of a bike garage was considered; in this case only the embodied impacts were assessed. The LCA impact assessment indicators employed in the reviewed studies are among the most commonly used in LCA studies on buildings [31, 32]. Apart from the GWP, the energy demand of the building was assessed through the cumulative energy demand (CED) [13-15, 17], or, as an alternative, the indicators from theCML 2001 method, namely the total renewable primary energy (RPE) and non-renewable primary energy (NRPE) Use [9-12, 18]. Other indicators are the ozone layer depletion potential (ODP) [9, 12, 17, 18], the acidification potential (AP) $[9,12,17,18]$, the eutrophication potential (EP) $[9,12,17,18]$, the abiotic resource depletion potential (ADP) $[12,18]$ and the photochemical oxidation creation potential (POCP) $[9,12$, 
17, 18]. The calculation of less common indicators, as exergy [33] or emergy [34], was disregarded, although their employment may provide further useful outcomes. Regarding the economic aspects, it is well known that these are among the first considerations that an investor or a building owner assesses before the beginning of a building design or renovation. Furthermore, with specific reference to the nearly zero-energy buildings defined by the European Energy Performance of Buildings Directive, it is suggested to compare many sets of building interventions to identify the cost-optimal combination [35]. Nevertheless, seven out of thirteen of the studies assessed the economic aspects of the interventions [11, 13-16]. In detail, three of these works compared the construction cost to the GWP in a multi-objective optimization study $[11,16]$, two studies included both investment and operating costs

[13] while the remaining two also accounted for the maintenance costs [14, 15]. Including embodied and operating terms for both costs and impacts in some multi-objective studies allowed for identifying that some indicators might be nonconflicting. In detail, embodied primary energy and embodied GWP [15] and CED and GWP [17] couples showed a quasi-linear relationship. For example, Kiss and Szalay highlighted that CED, GWP and POCP tend to the same direction in [17], as was shown by Montana et al. in [13-15] for embodied energy, embodied GWP and investment cost. Moreover, minimizing the Life Cycle Cost (LCC), CED and GWP in the same optimization led the space of objective functions to become a cloud of solutions with the Pareto Front being concentrated at the base of this cloud, although the proportionality relation between the functions is not exactly linear [15]. On the opposite, investment costs and embodied impacts were confirmed to be conflicting with operating energy demand [13-15] and with life cycle GWP [16].

\subsubsection{Variables Categories}

The variables usually assessed in the optimization of buildings energy performance can be grouped in five main categories:

Multicriteria-Oriented Optimization of Building Energy ... 251

- Early design parameters, as the building orientation or the number of floors;

- Opaque envelope components, as walls materials and thicknesses;

- Transparent envelope components, as windows glazing, frame or surface;

- Heating, ventilation and air-conditioning (HVAC) equipment features, as the rated size or the operation schedule of boilers or the share of heating provided by heat pumps and boilers;

- Renewable energy sources (RES) systems features, as photovoltaic (PV) and solar collectors' surfaces.

The "opaque components" category is the most commonly considered, and each of the studies assessed the optimal material or the optimal thickness at least for one envelope component. More in detail, the insulation material and thickness are the most popular variables, but also the use of concrete and bricks was optimized in some studies $[11,13,18]$. The assessment of the best HVAC was also common, although it was changed only parametrically and out of the optimization process in a couple of studies $[9,10]$. The heating system is the predominant topic, since most of the studies were performed in cold climates, while space cooling or ventilation technologies were hardly included in the LCA performance optimization [13, 16, 17]. Furthermore, the embodied impacts of the equipment were sometimes neglected [10]. Early design parameters were included only in three studies, with two of these assessing the optimal number of floors [17] and the third one the optimal position of the supporting columns of a garage [18]. This is due to the fact that the renovation of existing buildings is more common than design of new ones.

Since in optimization studies many variables are involved, assessing the influence of each one is hard. Furthermore, it is well known that the building physics is highly nonlinear, implying that the influence of a combination of interventions is different than the sum of the individual effects. Nevertheless, embodied impacts can be well approximated to be linear. For example, doubling the insulation thickness means more or less doubling the related embodied impacts, but the influence on the building heating and cooling loads cannot be predicted and specific calculations are needed. Anyway, having an indication on the influence of each intervention may help both designers and researchers in selecting the alternatives in a more conscious way. For this reason, Hollberg et al. performed many parametric analyses on the optimal insulation thickness with many insulation materials, heating systems and also time 
horizons [9, 10].

Although some aspects, as the embodied impacts in the heating systems, were neglected, this kind of results can really help future researchers in selecting a reasonable range of variables in their optimization studies, thus reducing the computational time and avoiding the risk of assessing useless or non-convenient values of variables. A recap of the main information provided on objective functions and variables is given in Table 3.

252 M. Francesco et al.

Table 3 Recap of the main features of the reviewed studies

Aim Objective functions Variables Reference

Design of a plus-energy

house

- Construction cost

- GWP

- Insulation thickness of

walls, floor and roof

- Windows area and

glazing

- Ventilation system

- PV modules

[16]

Refurbishment - GWP

NRPE was also assessed

- Insulation thickness

Service life, heating system

and insulation material

were changed

parametrically

[10]

Refurbishment - GWP

RPE, NRPE, ODP, AP, EP,

and POCP were also

assessed

- Insulation material and

thickness

Heating system and energy

mix were changed

parametrically

[9]

Design of a garage - GWP

PE, NRPE, ODP, AP, EP,

POCP, ADP (both mineral

and fossil fuels) were also

assessed

- Position of the columns

- Slab thickness

- Concrete quality

[18]

Refurbishment Construction cost/GWP

ratio

- Insulation material and

thickness

- Cladding material

- Heating system

[11]

Refurbishment - Construction cost

- GWP

NRPE was also assessed

- Insulation material and

thickness

- Cladding material

- Heating system

[11]

Refurbishment - RPE

- NRPE

- GWP

- ODP

$-\mathrm{AP}$

$-\mathrm{EP}$

- POCP 


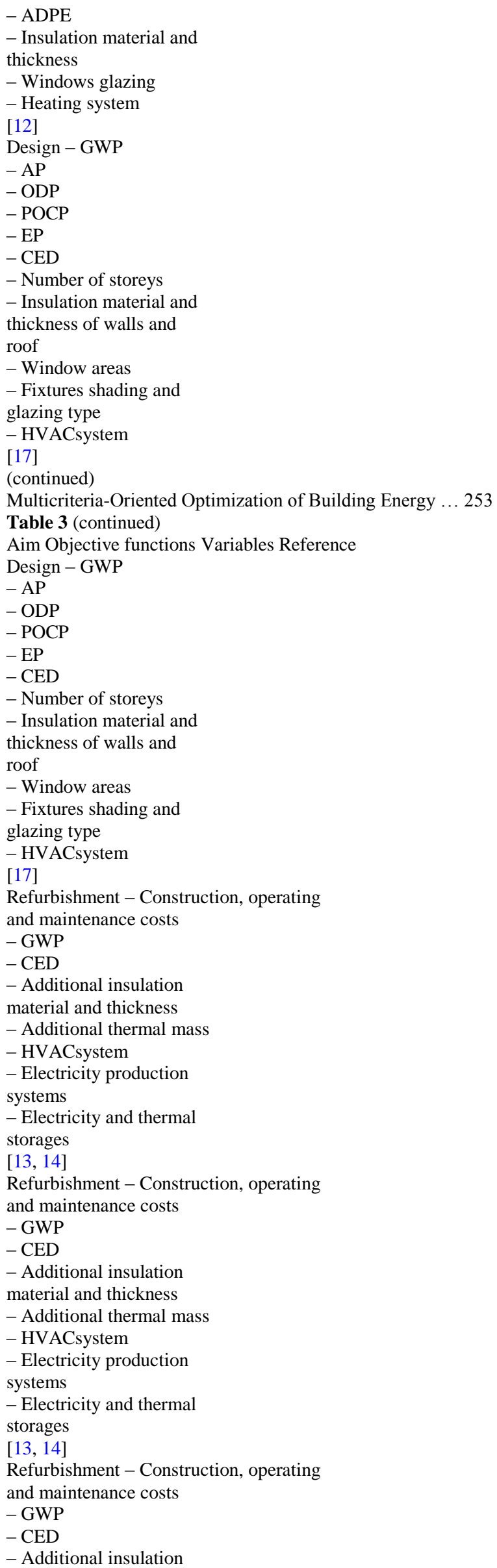


material and thickness

- Cladding replacement

- Transparent materials

glazing and frames

- HVACsystem

- PV modules

[15]

Refurbishment - Construction, operating

and maintenance costs

- GWP

$-\mathrm{CED}$

- Additional insulation

material and thickness

for each orientation

- Additional thermal mass

for each orientation

- Windows materials

glazing and frames for

each orientation

- HVACsystem

- Electricity production

systems

- Electricity and thermal

storages

[14]

254 M. Francesco et al.

\subsubsection{Constraints Setting and Management}

The constraints are relations used to limit the number of solutions obtained in an optimization study. In the space of solutions, they can be identified as lines or planes at the boundary. As an example, the absolute minimum value of the graph at the left in Fig. 7 is about -6.3 , but, if the space of solutions is constrained by the plane $z$ $=-3.5$, the feasible minimum of the problem becomes the circumference resulting from the intersection between the curve and the horizontal plane, as in the graph at the right in Fig. 7.

The constraints can be well managed in linear programming, since the optimum is located in one of the vertexes identified by the constraints, thus allowing to employ exact methods as the simplex algorithm to identify the best value of a problem. Nevertheless, despite the flexibility of heuristic and genetic algorithms, the solution of constrained optimization problems is not an easy task. Themost common approach is the adoption of penalty functions, converting the problem to an unconstrained optimization problem, although other approaches were developed in the literature [36] and in [16, 30]. In the reviewed papers, penalty functions were imposed to adopt a specific combination of insulation and cladding materials in [11] or to set a minimum distance between the supporting cement columns in [18]. The adoption of penalty functions requires defining meta-parameters for the penalty function. To avoid this, the constraint (of a positive annual energy balance) in [16, 30]was handled by integrating it as the first criterion (out of three) in the NSGA-II selection steps (reproduction and replacement). The two remaining criteria are the Pareto Front rank of the solution, and its Crowding distance. In other works [14, 15], constraints were imposed to specify the thermal features of windows, e.g. if the triple glazing is preferred to the double glazing, set the thermal transmittance to $x$ rather than to $y$, or to impose only one insulation material and only one cladding material on external walls or roof. These studies were developed on MOBO, that is equipped with an automatic constraint handling technique for most of the algorithms [25].

Fig. 7 Comparison between unconstrained (left) and constrained (right) optimization problem Multicriteria-Oriented Optimization of Building Energy ... 255

\subsection{Parameters and Data Quality}

The adoption of accurate data is a crucial issue in Life Cycle Assessment studies, since the results may be sensitive to site-specific conditions [37]. Nevertheless, optimization studies are often employed to obtain generic indications on the problem analysed in the study, adopting simplified mathematical models to quickly obtain an indication and then verifying the solutions through more detailed simulations [38]. According to this philosophy, all the studies analysed in this review employed secondary data, i.e. average data from literature, also in order to generalize their 
results. LCA impacts were drawn from LCA international databases as Ecoinvent [16, 17], KBOB [10, 11], Ökobau [9, 12, 15], or from the Environmental Product Declarations, i.e. reports based on ISO 14025 [39] and EN 15804 [40] standards that evaluate the LCA impacts of specific products, developed by companies in order to improve their sustainability or to show their attention to the environment-related issues [41]. In the same way, costs data were collected from databases $[15,16]$ or market reports [13].

\section{Results from the Annex 72 Case Studies 4.1 General Guidelines}

All the studies reviewed in this chapter can be included in a unique, genericworkflow, according to Fig. 8 [12]. In detail, the reference geometrical model of the building is first created and used as an input, indicating the building materials and layer thickness for each envelope component or the type of building services. In a second step, auxiliary information as the local climate or the reference period is defined. Subsequently, the variables are specified and the optimization run is started, assessing the embodied and use phase terms related to each impact function separately and then aggregating these terms (usually). The fitness function of each building configuration is assessed until the optimization ends, i.e.when a convergence criterion is satisfied or when the maximum number of iterations is reached. The results are then investigated in order to identify the variables behaviour in the best solutions and the optimal interventions to be adopted for the building.

\subsection{Building Envelope}

For a given heating/air conditioning system, very different interventions on the envelope were identified, up to the point of preferring no improvement (e.g. for heat pump heating powered by electricity from renewable sources) [9].

256 M. Francesco et al.

Fig. 8 General workflow for the optimization of buildings energy performance

Although it seems obvious, from the point of view of the associated impact,

materials of natural origin (e.g. cellulose) are preferred to synthetic ones (e.g. EPS), while an economic optimization suggests the opposite, since natural materials are more expensive [11].

Multicriteria-Oriented Optimization of Building Energy ... 257

\subsection{Renewable Energy Systems}

Very few of the analysed studies assessed the installation of RES. Montana et al. [15] proposed to install a rooftop photovoltaic system and solar thermal collectors in a large residential building, with both technologies being disregarded during the optimization, also because of the large number of variables assessed. In detail, the optimization preferred to install a district heating system instead of the solar collectors, maybe for cost-related reasons. The result did not take into account thermodynamic considerations, such as the temperature level at which heat must be supplied, but only the energy that can be provided by the different sources and the impacts incorporated into the systems (solar collectors vs. heat exchanger for heat pump or district heating, assuming the network being already installed).

On the opposite, results from [16] showed that the installation of PV should be promoted in addition to insulating the envelope (an optimal thickness being identified) as intervention optimizing both installation costs and GWP.

\subsection{Climate and Occupancy Influence}

Most of the reviewed studies regarded continental or oceanic climate cities, confirming that these countries aremore sensitive to the assessment of the energy and environmental impacts of buildings. In detail, one study was developed in Northern France [16], five in Germany [9-12], two in Denmark [13, 15], two in Southern Italy [5, 6] and two inHungary [17]. Thus, only two studies were focussed onmild climate, with one of them being a comparison of the performance of the same building in Mediterranean and oceanic climate. The outcomes of this study highlighted that the same insulationmaterials are optimal in both climates, with higher thicknesses being preferable in cold climates.

The existing variability in occupants' behaviour also influences the identification of the best solutions. In $[16,30]$, the optimization results with three types of households (single person, a retired couple and a young working couple with a child) were compared. Results of this study showed the existence of preferred solutions (e.g. 
triple glazing on the North East facade), but also solutions that strongly depend on the household kind, especially on the equipment features (e.g. the number of PV modules or the installation of a grey water heat recovery system).

\section{Conclusion}

This chapter described the research experience of IEA-EBC Programme Annex 72 members on the application of multi-objective optimization processes for selecting $258 \mathrm{M}$. Francesco et al.

the more suitable design or retrofit actions aimed at improving different aspects (energy, environmental, economic, etc.) of buildings in a life cycle perspective. Thirteen case studies were examined to identify and analyse different optimization approaches and to provide useful information to building designers and decisionmakers. As a generic summary of the present analysis, it is possible to highlight the difficulty in drawing generic guidelines on the methods for the optimization of life cycle performance of buildings. This ismainly due to the influence of approaches, software and algorithms, selected objective functions, variables, constraints and parameters, which are generally different for each selected study.

However, a generic methodological framework can be identified, starting from the preliminary building model development and ending with the identification of the optimal solutions (e.g. regarding building envelop, use of renewable energy technologies, influence of climate, occupancy and time horizon).

This framework, detailed case by case according to the peculiarities of the building under investigation, can help the stakeholders involved in the building design, construction and management in the selection of optimal interventions to be implemented.

\section{References}

1. Eurostat (2019) Complete energy balance 2019, edition 2019. https://ec.europa.eu/eurostat/ web/energy/data/energy-balances. Accessed 30 Sept 2019

2. International Energy Agency (IEA) (2018) Global alliance for buildings and construction (GlobalABC). 2018 global status report

3. European Parliament and Council (2010) Directive 2010/31/EU of 19 May 2010 on the energy performance of buildings (recast)

4. European Parliament and Council (2018) Directive (EU) 2018/844 of 30 May 2018 amending Directive 2010/31/EU on the energy performance of buildings and Directive 2012/27/EU on energy efficiency

5. International Organization for Standardization (ISO) (2006) ISO 14040:2006 — environmental management. Life cycle assessment. Principles and framework

6. InternationalOrganization for Standardization (ISO) (2017) ISO 14044:2006+Amd 1:2017environmental management. Life cycle assessment. Requirements and guidelines

7. European Committee for Standardization (CEN) (2011) EN 15978:2011 — sustainability of construction works. Assessment of environmental performance of buildings. Calculation method

8. International Energy Agency (IEA) (n.d.) IEA EBC Annex 72-assessing life cycle related environmental impacts caused by buildings. https://annex72.iea-ebc.org. Accessed 15 Sept 2020

9. Hollberg A, Ruth J (2014) A parametric life cycle assessment model for façade optimization. Build Simul Optim

10. Hollberg A, Ruth J (2013) Parametric performance evaluation and optimization based on life cycle demands. In: 8th energy forum on advanced building skins, Bressanone

11. Klüber N, Hollberg A, Ruth J (2014) Life cycle optimized application of renewable raw materials for retrofitting measures. In: World sustainable building 2014, Barcelona, pp 1-7

12. Hollberg A, Ruth J (2016) LCA in architectural design - a parametric approach. Int J Life Cycle Assess 21:943-960. https://doi.org/10.1007/s11367-016-1065-1

Multicriteria-Oriented Optimization of Building Energy ... 259

13. Cellura M, Longo S, Montana F, Riva Sanseverino E (2019) Multi-objective building envelope optimization through a life cycle assessment approach. In: 2019 IEEE International Conference on Environment and Electrical Engineering and 2019 IEEE Industrial and Commercial

Power Systems Europe (EEEIC/I\&CPS Europe), Genoa. Institute of Electrical and Electronics Engineers (IEEE), pp 1-6

14. Montana F (2020) Multi-objective optimization of buildings and building clusters performance: a life cycle thinking approach. University of Palermo

15. Montana F, Kanafani K, Wittchen KB, Birgisdottir H, Longo S, Cellura M, Riva Sanseverino E (2020) Multi-objective optimization of building life cycle performance. A housing renovation case study in Northern Europe. Sustainability 12(18):7807. https://doi.org/10.3390/su1 2187807

16. Recht T, Schalbart P, Peuportier B (2016) Ecodesign of a 'plus-energy' house using stochastic occupancy model, life-cycle assessment and multi-objective optimisation. In: Hamza N, 
Underwood C (eds) Building simulation and optimization conference, Newcastle upon Tyne 17. Kiss B, Szalay Z (2020) Modular approach to multi-objective environmental optimization of buildings. Autom Constr 111. https://doi.org/10.1016/j.autcon.2019.103044

18. Hollberg A, Heidenreich C, Ruth J, Hartung R, Herzog S (2014) Using evolutionary optimization for low-impact solid constructions. In: World sustainable building 2014, Barcelona

19. Robert McNeel\&Associates (n.d.) Rhinoceros web page. https://www.rhino3d.com/.Accessed 7 Apr 2020

20. TrimbleNavigation (n.d.) SketchUpwebsite. https://www.sketchup.com/.Accessed 3Apr 2020

21. Izuba Énergies (n.d.) PLEIADES software website. https://www.izuba.fr/logiciels/. Accessed 28 Aug 2020

22. U.S. Department of Energy (n.d.) EnergyPlus web page. https://energyplus.net/. Accessed 28 Apr 2020

23. International Organization for Standardization (ISO) (2008) ISO 13790:2008 — energy performance of buildings. Calculation of energy use for space heating and cooling

24. DIN (2011) DIN V 18599-2:2011—Energetische Bewertung von Gebäuden. Berechnung

des Nutz-, End- und Primärenergiebedarfs für Heizung, Kühlung, Lüftung, Trinkwasser und Beleuchtung. Teil 2: Nutzenergiebedarf für Heizen undKühlen vonGebäudezonen (in German) 25. Palonen M, Hamdy M, Hasan A (2013) MOBO a new software for multi-objective building performance optimization. In: 13th conference of international building performance simulation association, pp 2567-2574

26. MOBO web page (n.d.) https://ibpsa-nordic.org/tools.html. Accessed 27 Mar 2020

27. Gilles F, Bernard S, Ioannis A, Simon R (2017) Decision-making based on network visualization applied to building life cycle optimization. Sustain Cities Soc 35:565-573. https://doi.org/ $10.1016 /$ j.scs.2017.09.006

28. Wortmann T (2019) Genetic evolution vs. function approximation: benchmarking algorithms for architectural design optimization. J Comput Des Eng 6:414-428. https://doi.org/10.1016/ j.jcde.2018.09.001

29. Longo S, Montana F, Riva SE (2019)Areviewon optimization and cost-optimal methodologies in low-energy buildings design and environmental considerations. Sustain Cities Soc 45:87-104 30. Recht T (2016) Study of the ecodesign of plus-energy houses (Étude de l'écoconception de maisons à énergie positive, in French). PSL Research University (prepared in MINES ParisTech)

31. Bahramian M, Yetilmezsoy K (2020) Life cycle assessment of the building industry: an overview of two decades of research (1995-2018). Energy Build 109917

32. Lasvaux S, Favre D, Périsset B, Bony J, Hildbrand C, Citherlet S (2015) Life cycle assessment of energy related building renovation: methodology and case study. Energy Procedia 78:34963501. https://doi.org/10.1016/j.egypro.2016.10.132

33. De Meester B, Dewulf J, Verbeke S, Janssens A, Van Langenhove H (2009) Exergetic lifecycle assessment (ELCA) for resource consumption evaluation in the built environment. Build Environ 44:11-17. https://doi.org/10.1016/j.buildenv.2008.01.004

$260 \mathrm{M}$. Francesco et al.

34. Reza B, Sadiq R, Hewage K (2014) Emergy-based life cycle assessment (Em-LCA) of multiunit and single-family residential buildings in Canada. Int J Sustain Built Environ 3:207-224. https://doi.org/10.1016/j.ijsbe.2014.09.001

35. European Commission (2012) Commission Delegated Regulation (EU) No 244/2012 of 16 January 2012 supplementing Directive 2010/31/EU of European Parliament and of the Council 36. Chehouri A, Younes R, Perron J, Ilinca A (2016) A constraint-handling technique for genetic algorithms using a violation factor. J Comput Sci 12:350-362

37. Cellura M, Longo S, Mistretta M (2011) Sensitivity analysis to quantify uncertainty in life cycle assessment: the case study of an Italian tile. Renew Sustain Energy Rev 15-9:4697-4705 https://doi.org/10.1016/j.rser.2011.07.082,ISSN1364-0321

38. Pereira S, Ferreira P, Vaz AIF (2015) A simplified optimization model to short-term electricity planning. Energy 93:2126-2135. https://doi.org/10.1016/j.energy.2015.10.040 39. International Organization for Standardization (ISO) (2006) ISO 14025:2006 - environmental labels and declarations - type III environmental declarations - principles and procedures 40. European Committee for Standardization (CEN) (2012) EN 15804:2012 - sustainability of construction works. Environmental product declarations. Core rules for the product category of construction products

41. The International EPD® System (n.d.) Environmental product declarations (EPD). https:// www.environdec.com/. Accessed 27 Mar 2020 